\title{
Disturbances in branched-chain amino acid profile and poor daily functioning in mildly depressed chronic obstructive pulmonary disease patients
}

Marisa R. Pinson ${ }^{1,2}$, Nicolaas E. P. Deutz ${ }^{1}$, Rajesh Harrykissoon ${ }^{3}$, Anthony J. Zachria ${ }^{3}$ and Mariëlle P. K. J. Engelen ${ }^{\text {1* }}$

\begin{abstract}
Background: Depression is one of the most common and untreated comorbidities in chronic obstructive pulmonary disease (COPD), and is associated with poor health outcomes (e.g. increased hospitalization/exacerbation rates). Although metabolic disturbances have been suggested in depressed non-diseased conditions, comprehensive metabolic phenotyping has never been conducted in those with COPD. We examined whether depressed COPD patients have certain clinical/functional features and exhibit a specific amino acid phenotype which may guide the development of targeted (nutritional) therapies.
\end{abstract}

Methods: Seventy-eight outpatients with moderate to severe COPD (GOLD II-IV) were stratified based on presence of depression using a validated questionnaire. Lung function, disease history, habitual physical activity and protein intake, body composition, cognitive and physical performance, and quality of life were measured. Comprehensive metabolic flux analysis was conducted by pulse stable amino acid isotope administration. We obtained blood samples to measure postabsorptive kinetics (production and clearance rates) and plasma concentrations of amino acids by LC-MS/MS. Data are expressed as mean [95\% Cl]. Stats were done by graphpad Prism 9.1.0. a $<0.05$.

Results: The COPD depressed (CD, $n=27)$ patients on average had mild depression, were obese (BMI: 31.7 [28.4, $\left.34.9] \mathrm{kg} / \mathrm{m}^{2}\right)$, and were characterized by shorter 6 -min walk distance $(P=0.055)$, physical inactivity $(P=0.03)$, and poor quality of life $(P=0.01)$ compared to the non-depressed $\operatorname{COPD}(C N, n=51)$ group. Lung function, disease history, body composition, cognitive performance, and daily protein intake were not different between the groups. In the CD group, plasma branched chain amino acid concentration (BCAA) was lower $(P=0.02)$, whereas leucine $(P=0.01)$ and phenylalanine $(P=0.003)$ clearance rates were higher. Reduced values were found for tyrosine plasma concentration $(P=0.005)$ even after adjustment for the large neutral amino acid concentration ( $=$ sum BCAA, tyrosine, phenylalanine and tryptophan) as a marker of dopamine synthesis $(P=0.048)$.

Conclusion: Mild depression in COPD is associated with poor daily performance and quality of life, and a set of metabolic changes in depressed COPD that include perturbation of large neutral amino acids, specifically the BCAAs.

\footnotetext{
*Correspondence: mpkj.engelen@ctral.org

${ }^{1}$ Department of Health and Kinesiology, Center for Translational Research

in Aging and Longevity, Texas A\&M University, College Station, TX, USA

Full list of author information is available at the end of the article
} original author(s) and the source, provide a link to the Creative Commons licence, and indicate if changes were made. The images or other third party material in this article are included in the article's Creative Commons licence, unless indicated otherwise in a credit line to the material. If material is not included in the article's Creative Commons licence and your intended use is not permitted by statutory regulation or exceeds the permitted use, you will need to obtain permission directly from the copyright holder. To view a copy of this licence, visit http://creativecommons.org/licenses/by/4.0/. The Creative Commons Public Domain Dedication waiver (http://creativeco mmons.org/publicdomain/zero/1.0/) applies to the data made available in this article, unless otherwise stated in a credit line to the data. 
Trial registration clinicaltrials.gov: NCT01787682, 11 February 2013-Retrospectively registered; NCT02770092, 12 May 2016-Retrospectively registered; NCT02780219, 23 May 2016-Retrospectively registered; NCT03796455, 8 January 2019-Retrospectively registered.

Keywords: COPD, Depression, Branched-chain amino acids, Physical performance

\section{Background}

Amongst the three chronic conditions that affect 60 million people in the USA (diabetes, heart disease, and chronic obstructive pulmonary disease (COPD)), patients with COPD have the highest prevalence of depression. Depression is one of the most common and untreated comorbidities in COPD [1], affecting 16-71\% of patients with moderate to severe COPD [2-6]. Even conservatively, this is nearly twice the average for the U.S. population as a whole (7.1\% prevalence in 2017) [7].

Depression in COPD is associated with reduced quality of life (QoL), worse treatment compliance, and higher rates of acute exacerbations [8-11]. As a result, COPD patients with depression are more likely to have an emergency room visit (48\%) and hospitalization (60\%) [8], and have significantly more relapses [12]. Frequent exacerbations, on the other hand, give rise to a poor QoL, resulting in a vicious circle. Conflicting evidence exists whether changes in body composition may influence depression status in COPD $[9,13-18]$ and remains to be clarified as additional studies are done.

\section{Physical function and cognition}

COPD patients with higher levels of depressive symptoms report worse daily physical functioning $[19,20]$ and have lower functional capacity (e.g., 6 min walk test, incremental tests) [21-24]. These patients are more likely to use oxygen during the test $[9,16,25]$. Additionally, other studies linked depression to skeletal muscle weakness [26] and decreased physical activity [13]. While many have shown a link between depression and cognitive impairment in the general population, studies focused on COPD patients have not yet definitively shown such a link [13, 27, 28].

\section{Metabolic phenotype}

Although COPD is associated with amino acid metabolic deregulations [29-34], limited research has been conducted examining the role of amino acid perturbations as potential metabolic mechanisms underlying depression in COPD. Impaired plasma levels of tryptophan, a precursor of serotonin, have previously been observed in depressed patients (without COPD) as reflected by a reduced ratio of tryptophan to large neutral amino acids (LNAA which include tyrosine, phenylalanine, and the branched-chain amino acids (BCAA)). When depression scores improved in depressed patients, there was a corresponding increase in tryptophan/LNAA ratio, meaning more tryptophan can cross the blood brain barrier with less competition for the transporter [35]. The brain tryptophan concentration was found to be related to the cerebral serotonin synthesis [36]. In addition, decreased levels of BCAAs have previously been identified in COPD patients and particularly in those with muscle loss [29, 37], potentially contributing to increased risk for depression. Furthermore, decreased bioavailability of arginine has been observed in major depressive disorder $[38,39]$ and altered arginine metabolism has been identified in COPD [33], suggesting an additional pathway by which altered amino acid metabolism may contribute to depression in COPD patients.

To identify whether depression in COPD is associated with a specific metabolic phenotype, we examined in the present study whether higher depression scores were associated with specific changes in plasma amino acid profile and whole-body production rates of amino acids known to play a role in mood (e.g. LNAA, BCAA, and arginine). COPD patients were recruited from the MEDIT trial (MEtabolism of Disease with Isotope Tracers). As multiple other factors may also affect amino acid metabolism, the subjects were well characterized by general- and disease specific features (e.g. lung function, disease history, comorbidity index, habitual dietary intake, physical activity level), body composition, muscle and cognitive function. Identification of a metabolic phenotype in a depressed COPD population may help to gain insight into the underlying pathophysiological mechanisms contributing to increased risk for depression, guiding a more targeted antidepressant treatment and revealing potential targets for nutritional intervention.

\section{Materials and methods}

\section{Subjects}

Subjects with COPD were recruited from the MEDIT (MEtabolism of Disease with Isotope Tracers) trial, a large controlled trial in healthy and diseased subjects. Patients with clinically stable COPD under the routine management of the pulmonary clinics were recruited. COPD subjects were further subdivided into nondepressed with COPD and depressed with COPD based on recorded Hospital Anxiety and Depression Scale depression subsection score (a score of 8 or higher was 
used to define clinically relevant depression) [10, 40-42]. In the non-depressed with COPD group, only subjects with a depression score of less than 8 were included (non-depressed). Groups controlled for age by selecting subjects to have comparable age ranges between groups. In total, 178 subjects were assessed for eligibility, 27 depressed COPD (CD group) and 51 non-depressed COPD (CN group) subjects were included for data analysis. The inclusion criteria for all groups were age 46 to 76 years old in order to control for variances due to age, and the ability to walk, sit, and stand independently. All COPD patients were clinically stable with no history of exacerbation of their disease or a respiratory tract infection at least 4 weeks prior to the study. As previously described, the exclusion criteria were the presence of a fever within 3 days prior to the study day, acute illness, a metabolically unstable chronic illness, pre-existing untreated metabolic or renal disease, malignancy, recent surgery, and use of oral corticosteroids 1 month prior to the study because of known effects on amino acid metabolism $[43,44]$. As part of the screening process, a medical history was conducted which included the number of exacerbations and medication used. Study days started in the morning under postabsorptive conditions (no food after 12 a.m.) and lasted $5 \mathrm{~h}$.

All subjects were studied at the Clinical Research Unit of the Center for Translational Research in Aging and Longevity, housed at the Human Clinical Research Building, Texas A\&M University. Before any measurements were performed, written informed consent was obtained from all subjects. The study was conducted in accordance with the Declaration of Helsinki, and the protocol was approved by the Institutional Review Board of Texas A\&M University before being registered on ClinicalTrials.gov (NCT01787682, NCT02770092, NCT02780219, NCT03796455).

\section{Diet, physical activity, COPD severity, comorbidity assessment, and quality of life questionnaires}

Habitual dietary intake was assessed by 24-h dietary recall, and habitual physical activity level by Physical Activity Scale for the Elderly Questionnaire (PASE) [45]. The COPD Assessment Test (CAT) [46] was performed to assess the level of dyspnea, and Charlson index for assessment of associated comorbidities [47]. The category of Cardiovascular Disease is composed of hypertension, congestive heart failure, myocardial infarction, peripheral vascular disease, cerebrovascular disease, pulmonary circulation disorders, and dyslipidemia. Profile of Mood States (POMS) Questionnaire was used to quantify negative and total mood states [48]. St. George Respiratory Questionnaire (SGRQ) was used to assess disease specific quality of life [49]. A change in the total score for the SGRQ that represents a clinically important difference is 4 units [50].

\section{Anthropometrics, body composition, and lung function}

All study procedures were identical in both groups and conducted as previously described [44]. Briefly, a digital beam scale and stadiometer were used to measure body weight and height. Blood pressure was measured on the upper arm after a 5 min rest sitting. Whole body, trunk and extremity (arms and legs) fat mass (FM), and fat-free mass (FFM) were obtained from all subjects while in a supine position by dual-energy X-ray absorptiometry (Hologic QDR 4500/Version 12.7.3.1 (Bedford, MA)). Anthropometric and body composition were standardized for height $\left(\mathrm{kg} / \mathrm{m}^{2}\right)$ [51] to obtain the body mass index (BMI, $\mathrm{kg} / \mathrm{m}^{2}$ ), fat free mass index (FFMI), fat mass index (FMI), and the appendicular skeletal muscle index (ASMI). Spirometry was performed using the Microloop Peak flow Meter (CareFusion, San Diego, CA). Forced expiratory volume in $1 \mathrm{~s}$ (FEV1) and forced vital capacity (FVC) was measured in all participants, with the highest value from $\geq 3$ technically acceptable maneuvers being used [52]. Transcutaneous oxygen saturation was measured using pulse oximetry.

\section{Physical function}

Markers of physical function included assessment of upper and lower limb skeletal muscle function, gait speed, and the 6-min walk test (6MWT) and were conducted as done previously [44]. Briefly, leg strength was quantified by using a Kincom isokinetic dynamometry (Isokinetic International, Chattanooga, TN, USA) to measure the peak leg force during one leg reciprocal extensions (at $60^{\circ} / \mathrm{s}$ ) [53, 54]. Handgrip strength was quantified by using a Vernier dynamometry (Vernier software and Technology, Beaverton, OR, USA) to measure the peak handgrip force that the subject was able to generate out of 3 reproducible repetitions, with $1 \mathrm{~min}$ of rest between each attempt [53]. Leg endurance was assessed by performing 30 maximal single leg extensions (at $120^{\circ} / \mathrm{s}$ ) to assess a decrease in leg force output [54]. The average force output of the last 3 repetitions as percentage of the first 3 repetitions was used (e.g. (avg first 3 -avg last 3)/avg first 3). $6 \mathrm{MWT}$ was performed as per American Thoracic Society standards [55]. Subjects had access to their walking aid and/or oxygen if required.

\section{Neurocognitive function}

Subjects completed the Trail Making Test (TMT) [56] and Stroop color-word tests (SCWTs) [57], which are known to be simple and sensitive in assessing neurocognitive impairment. TMT consists of two subtasks, Part A 
and Part B. SCWTs consists of three subtasks (I, II, and III), and the interference score was calculated $[58,59]$.

\section{Blood analysis to assess markers of metabolic/clinical health}

Arterialized-venous blood was put in Li-heparinized or EDTA tubes (Becton Dickinson Vacutainer system, Franklin Lakes, New Jersey, USA), immediately put on ice to minimize enzymatic reactions and was centrifuged at $4{ }^{\circ} \mathrm{C}, 3120 \times \mathrm{g}$ for $5 \mathrm{~min}$ to isolate plasma. A part of the plasma was aliquoted into tubes with 0.1 vol of $33 \%$ $(\mathrm{w} / \mathrm{w})$ trichloroacetic and then vortexed for the denaturation of proteins. Samples were immediately frozen and stored at $-80{ }^{\circ} \mathrm{C}$ for later processing. Plasma amino acid concentrations of the essential amino acids, tryptophan, large neutral amino acids (LNAA), and the branchedchain amino acids (BCAA) were analyzed batch-wise by LC-MS/MS by isotope dilution, as previously reported [60]. High-sensitivity C-reactive protein (hs-CRP) was measured using a particle enhanced immuno-turbidimetric assay, and fasting glucose concentration was measured using a hexokinase method (Cobas c111, Roche Diagnostics, Mannheim, Germany). Homeostatic model assessment (HOMA) index was calculated to assess $\beta$-cell function and insulin resistance [61].

\section{Stable tracer infusion by IV pulse administration}

As previously described [60], a peripheral line was placed in a vein of the lower arm for stable tracer infusions and in a superficial dorsal vein of the contralateral hand for blood sampling. A venous blood sample was initially collected to measure baseline enrichment. Then an IV pulse containing a cocktail of amino acid stable tracers (Cambridge Isotope Laboratories: Woburn, MA, USA) was administered, as described previously [60]. Arterialized-venous blood was sampled at multiple time points $(t=10,20,30,60$, and $120 \mathrm{~min})$ for $2 \mathrm{~h}$ after pulse administration.

Whole-body production (WBP) rates were calculated with non-compartmental analysis using GraphPad Prism (Version 9.2.0). WBP for all amino acids was calculated as tracer pulse dose/area under the curve (AUC) from $t=10$ to $t=120 \mathrm{~min}$ [62]. AUC was calculated by fitting the decay of the TTR of the stable tracers that were injected with the pulse with either two exponentials: TTR $(t)=a$ * $\exp \left(-k 1^{*} t\right)+b * \exp (-k 2 * t)$ or three exponentials: TTR $(\mathrm{t})=\mathrm{a} * \exp (-\mathrm{k} 1 * \mathrm{t})+\mathrm{b} * \exp (-\mathrm{k} 2 * \mathrm{t})+\mathrm{c} * \exp (-\mathrm{k} 3 * \mathrm{t})$ [63]. Conversion of one amino acid into another amino acid was done by using the WBP of the product amino acid and AUC of the TTR from pulse of the product/substrate [60]. Clearance of the stable tracers was calculated as WBP/plasma concentration [64].

\section{Statistical analysis}

All results were expressed as means [95\% CI] or geometric means [95\% CI] when data was log-transformed. The normality of the data was tested by the D'AgostinoPearson omnibus normality test. The Robust regression and Outlier removal (ROUT) test $(\mathrm{Q}=5 \%)$ were performed on normal data to identify outliers. An one-way ANCOVA was used to compare the groups (CN vs. $C D)$. Covariates used in all analyses included BMI and age, as these are known to influence amino acid metabolism and did change our findings when included as covariates. We checked to see if including antidepressant use, SSRI use, SNRI use, anxiolytic use, sex, FEV1, smoking status, CRP, carbohydrate intake, and comorbidities as a covariate altered ANCOVA results and observed no difference (data not shown), so therefore did not include these variables as a covariate in analyses. When the normality test failed, data was transformed using natural log to normalize and then analyzed when normality was confirmed. The statistical packages within GraphPad Prism (GraphPad Software, La Jolla, CA, Version 9) were used for data analysis. The significance level was set at q value $(<0.05)$ which is the Benjamini-Hochberg FDR corrected $P$ value.

\section{Results}

Demographics, clinical characteristics, and comorbidities The depressed COPD group (CD) was characterized by mild depression (depression scores: 9.185 [8.545, 9.825]) and had on average a BMI $>30 \mathrm{~kg} / \mathrm{m}^{2}$ (BMI: 31.65 [28.40, $34.90] \mathrm{kg} / \mathrm{m}^{2}$ ), which is classifiable as obese (Table 1 ). In contrast, the non-depressed COPD $(\mathrm{CN})$ on average had a $\mathrm{BMI}<30 \mathrm{~kg} / \mathrm{m}^{2}$ (BMI: 29.08 [27.30, 30.85] kg/m²), though this was not statistically different from CD. The $\mathrm{CD}(\mathrm{n}=27)$ and $\mathrm{CN}(\mathrm{n}=51)$ groups were of a similar age range (46-76 years) and had comparable lung function, $\mathrm{O}_{2} \%$ saturation, $\mathrm{O}_{2}$ use, and GOLD score distribution (1: $9.8 \%$ CN v. $7.4 \%$ CD, 2: $29.4 \%$ v. $25.9 \%$, 3: $33.3 \%$ v. $40.7 \%$, 4: $27.5 \%$ v. $25.9 \%$ ). While the $\mathrm{CD}$ and $\mathrm{CN}$ groups had comparable COPD severity, dyspnea symptoms and disease history (exacerbation and hospitalization frequency in preceding year), the $C D$ group had higher CAT scores $(P=0.003$; Fig. $1 \mathrm{~A}$ and Table 1$)$, indicating a higher COPD impact on their life. Systolic blood pressure $(P=0.036)$ and CRP $(P=0.007)$, as a marker of systemic inflammation, were lower in CD but no differences were found in insulin or glucose plasma concentrations, between the groups (Table 2). Although medication use and Charlson comorbidity index were comparable between the groups, a higher rate of sleep disordered breathing was observed in the $\mathrm{CD}$ group $(13.7 \% \mathrm{CN}$ v. $44.4 \% \mathrm{CD}, P=0.005$ ) (Table 1 ). Additionally, there was a 
Table 1 Demographics, clinical characteristics, and comorbidities of the non-depressed and depressed COPD groups

\begin{tabular}{|c|c|c|c|c|}
\hline & $\begin{array}{l}\text { COPD non-depressed (CN) } \\
(n=51)\end{array}$ & $\begin{array}{l}\text { COPD depressed (CD) } \\
(n=27)\end{array}$ & Estimated difference & $\begin{array}{l}\text { Unpaired t-test } \\
p \text { value }\end{array}$ \\
\hline \multicolumn{5}{|l|}{ Demographics } \\
\hline Age (years) & $64.72[63.16,66.28]$ & $64.04[57.90,69.64]$ & $-0.68[-3.60,2.24]$ & 0.643 \\
\hline Sex (male/female) & $26 / 25$ & $13 / 14$ & & $>0.999$ \\
\hline Level of education (score) & $2.19[1.56,2.81]$ & $2.00[1.39,2.62]$ & $-0.19[-1.15,0.78]$ & 0.698 \\
\hline \multicolumn{5}{|l|}{ General characteristics } \\
\hline Body weight (kg) & $79.03[73.15,85.38]$ & $83.96[74.03,95.23]$ & $5.76[-4.93,16.45]$ & 0.384 \\
\hline Height (m) & $1.67[1.64,1.70]$ & $1.66[1.63,1.69]$ & $-0.01[-0.05,0.03]$ & 0.667 \\
\hline Body Mass Index $\left(\mathrm{kg} / \mathrm{m}^{2}\right)$ & $29.08[27.30,30.85]$ & $31.65[28.40,34.90]$ & $2.574[-0.75,5.90]$ & 0.128 \\
\hline \multicolumn{5}{|l|}{ COPD parameters } \\
\hline FEV1 (\% of predicted) & $43.86[38.94,48.79]$ & $44.59[37.13,52.06]$ & $-1.66[-9.01,5.69]$ & 0.911 \\
\hline GOLD stage (I/II/III/IV) & $5 / 15 / 17 / 14$ & $2 / 7 / 11 / 7$ & & 0.765 \\
\hline Years of COPD related symptom (yr) & $11.81[8.74,14.88]$ & $10.21[7.18,13.24]$ & $-1.51[-51.87,48.86]$ & 0.644 \\
\hline $\begin{array}{l}\text { No. of hospitalizations past year for exacerba- } \\
\text { tion }\end{array}$ & $0.24[0.07,0.42]$ & $0.42[0.12,0.73]$ & $0.26[-0.06,0.57]$ & 0.267 \\
\hline No. of exacerbations in the past year & $0.57[0.25,0.89]$ & $1.00[0.29,1.71]$ & $0.56[-0.12,1.24]$ & 0.203 \\
\hline O2 use (no/yes) & $30 / 21$ & $11 / 16$ & & 0.157 \\
\hline mMRC dyspnea grade & $2.20[1.92,2.49]$ & $2.48[2.14,2.82]$ & $0.32[-0.15,0.79]$ & 0.238 \\
\hline CAT score & $16.71[13.48,19.94]$ & $25.27[21.16,29.38]$ & $9.04[3.47,14.61]$ & 0.003 \\
\hline Current smoker (yes/no) & $29 / 21$ & $18 / 8$ & & 0.456 \\
\hline Years smoking & $34.57[30.00,40.00]$ & $34.50[30.00,40.00]$ & $1.57[-3.76,6.91]$ & 0.619 \\
\hline Smoke pack years & $46.31[32.00,45.00]$ & $48.96[25.00,66.00]$ & $1.74[-13.19,16.65]$ & 0.716 \\
\hline \multicolumn{5}{|l|}{ Vitals } \\
\hline Heart rate (bpm) & $70.90[66.00,73.00]$ & $75.48[67.00,83.00]$ & $5.02[-0.44,10.47]$ & 0.090 \\
\hline Systolic BP (mmHg) & $137.20[127.00,141.00]$ & $130.20[117.00,142.00]$ & $-8.81[-16.79,-0.84]$ & 0.085 \\
\hline Diastolic BP (mmHg) & $78.41[76.00,82.00]$ & $77.33[71.00,83.00]$ & $-1.78[-5.83,2.28]$ & 0.594 \\
\hline Temperature $\left({ }^{\circ} \mathrm{C}\right)$ & $36.52[36.40,36.67]$ & $36.57[36.17,36.94]$ & $0.07[-0.13,0.26]$ & 0.589 \\
\hline O2 saturation (\%) & $95.31[94.00,97.00]$ & $94.81[94.00,97.00]$ & $-0.46[-2.014,1.10]$ & 0.155 \\
\hline \multicolumn{5}{|l|}{ Comorbidities } \\
\hline Charlson comorbidity index (score) & $1.80[1.52,2.09]$ & $1.93[1.58,2.27]$ & $0.30[-0.07,0.67]$ & 0.446 \\
\hline Cardiovascular disease (yes/no) & $32 / 19$ & $20 / 7$ & & 0.449 \\
\hline Diabetes (yes/no) & $12 / 39$ & $6 / 21$ & & $>0.999$ \\
\hline Glucose intolerance (yes/no) & $5 / 46$ & $2 / 25$ & & $>0.999$ \\
\hline Obstructive sleep apnea (yes/no) & $19 / 32$ & $15 / 12$ & & 0.153 \\
\hline Sleep disordered breathing (yes/no) & $7 / 44$ & $12 / 15$ & & 0.005 \\
\hline Osteoporosis (yes/no) & $3 / 48$ & $1 / 25$ & & $>0.999$ \\
\hline Other neurological disorders (yes/no) & $6 / 45$ & $5 / 22$ & & 0.499 \\
\hline Cognitive deficit (yes/no) & $3 / 48$ & $2 / 25$ & & $>0.999$ \\
\hline Psychological issues (yes/no) & $21 / 30$ & $13 / 14$ & & 0.634 \\
\hline Dementia (yes/no) & $2 / 49$ & $0 / 27$ & & 0.542 \\
\hline \multicolumn{5}{|l|}{ Medications } \\
\hline Antianxiety or antidepressant agent (yes/no) & $24 / 27$ & $16 / 11$ & & 0.474 \\
\hline Anxiolytic agent (yes/no) & $7 / 44$ & $4 / 23$ & & $>0.999$ \\
\hline Antidepressant (yes/no) & $23 / 28$ & $15 / 12$ & & 0.477 \\
\hline SSRI (yes/no) & $16 / 35$ & $9 / 18$ & & $>0.999$ \\
\hline SNRI (yes/no) & $10 / 41$ & $3 / 24$ & & 0.525 \\
\hline Antipsychotic (yes/no) & $5 / 45$ & $4 / 23$ & & 0.712 \\
\hline
\end{tabular}

Values are mean $[95 \% \mathrm{Cl}]$, except for when data was log-transformed for which geometric mean $[95 \% \mathrm{Cl}]$ was used. Education level: $0=$ Associate, $1=$ Bachelor, $2=$ Master, 3 =Doctoral or professional degree. FEV1: Forced Expiratory Volume in $1 \mathrm{~s}$. O2: supplemental oxygen, mMRC: modified medical research council dyspnea scale. Statistics are by unpaired t-test, normal text is untransformed data and italicized is log-transformed data, bold is $P<0.05$ 

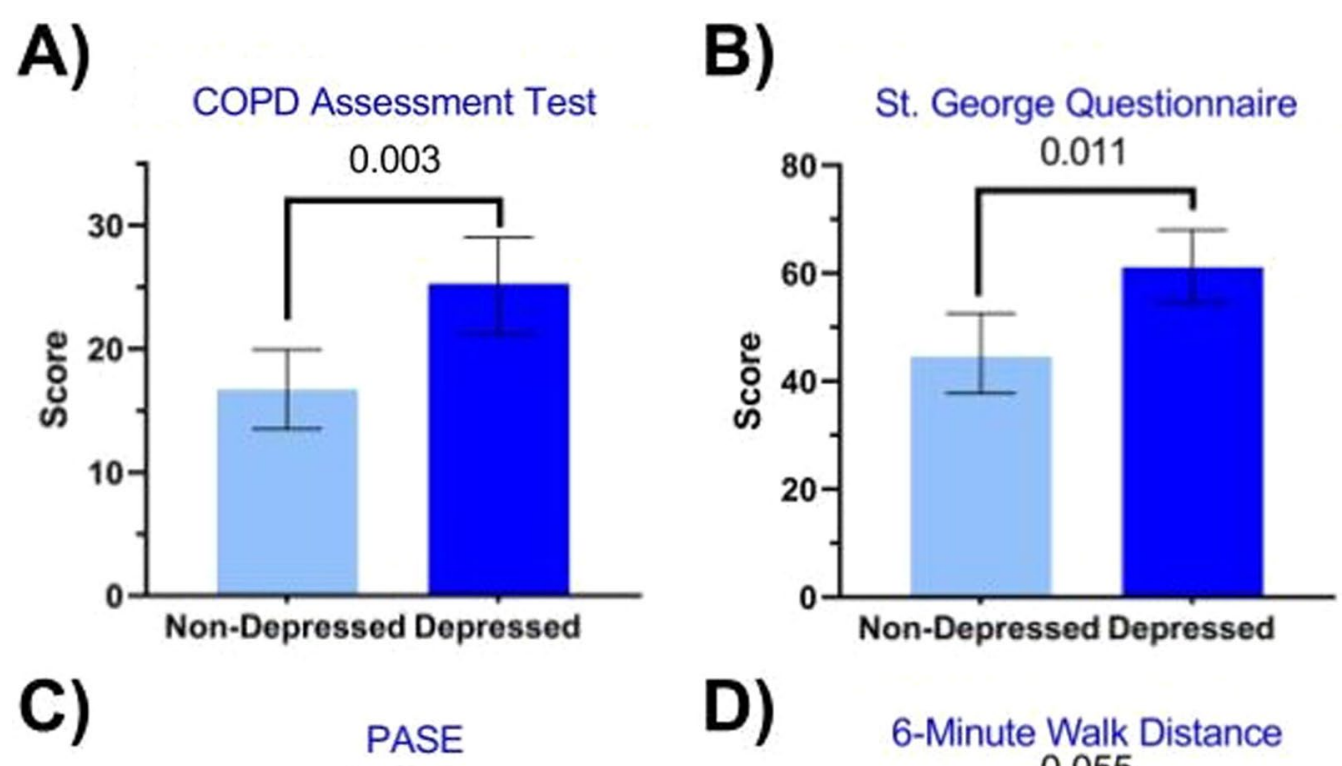

D)
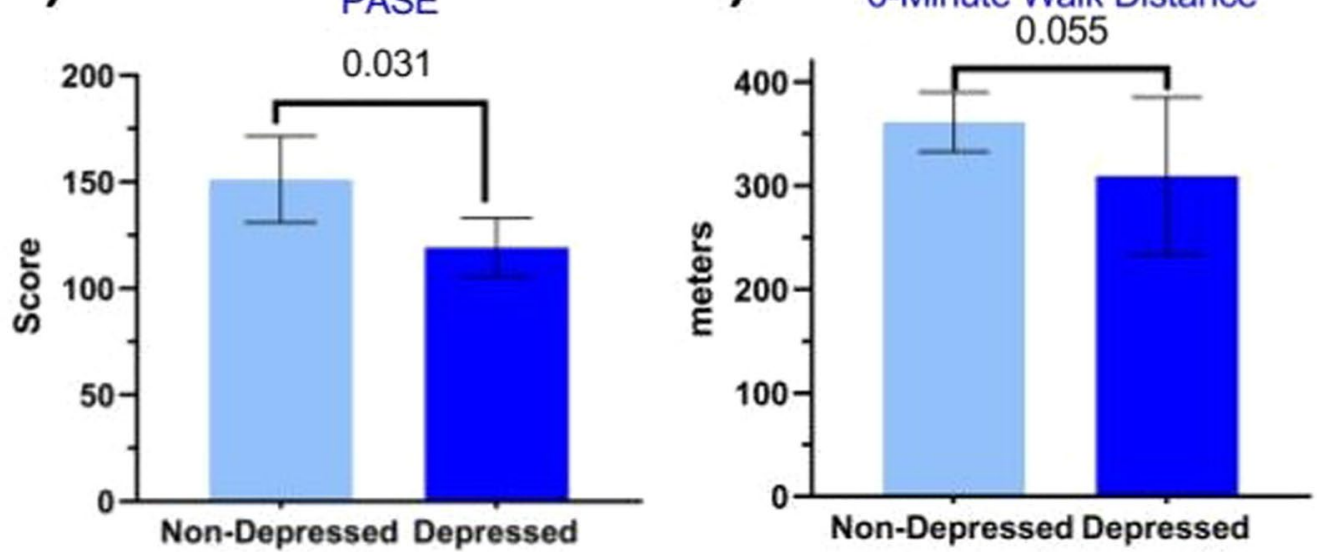

Fig. 1 Quality of life and physical function in non-depressed and depressed COPD patients. A COPD assessment test measuring impact of COPD on patient's health. B Total score of St. George Questionnaire including Symptoms, Activities, and Impacts. C Physical Activity Scale for the Elderly (PASE). D Total distance traveled during 6-Min Walk Test. Mean $\pm 95 \%$ Cl by ANCOVA with age and BMI as covariates

Table 2 Blood measurements of the non-depressed and depressed COPD groups

\begin{tabular}{lcccc}
\hline & $\begin{array}{l}\text { COPD non-depressed (CN) } \\
(\mathbf{n}=\mathbf{5 1})\end{array}$ & $\begin{array}{l}\text { COPD depressed (CD) } \\
(\mathbf{n}=\mathbf{2 7})\end{array}$ & $\begin{array}{c}\text { Estimated difference } \\
\boldsymbol{p} \text { value }\end{array}$ \\
\hline Blood measurements & & & & \\
CRP (mg/L) & $6.81[4.19,9.42]$ & $5.72[1.77,9.66]$ & $-2.27[-6.69,2.15]$ & $\mathbf{0 . 0 0 7}$ \\
Glucose (mmol/L) & $5.79[5.54,6.05]$ & $5.74[5.36,6.12]$ & $-0.19[-0.61,0.24]$ & 0.410 \\
Insulin (ulU/mL) & $13.71[9.30,18.11]$ & $12.99[7.09,18.88]$ & $-1.15[-8.34,6.04]$ & 0.490 \\
HOMA Index & $3.79[2.44,5.13]$ & $3.28[1.65,4.92]$ & $-0.69[-2.13,0.74]$ & 0.354 \\
\hline
\end{tabular}

Values are mean [95\% Cl], except for when data was log-transformed for which geometric mean [95\% CI] was used. CRP: C-reactive protein. Homeostatic model assessment (HOMA) is a method for assessing $\beta$-cell function and insulin resistance. Statistics are by ANCOVA with age and BMI as covariates, normal text is untransformed data and italicized is log-transformed data, bold is $P<0.05$

higher prevalence in CD of sleep apnea (37.3\% v. 55.6\%) and cardiovascular disease $(62.7 \% \mathrm{CN}$ v. $74.1 \% \mathrm{CD})$ though both were not significant. Furthermore, there was no difference in prevalence of self-reported psychological issues $(41.2 \% \mathrm{CN}$ v. $48.1 \% \mathrm{CD})$ and no difference in the proportion of patients using antidepressants/anxiolytics 
between non-depressed COPD and those experiencing depression (48\% CN vs. 59\% CD).

\section{Systemic health Wellbeing, quality of life, and lifestyle}

Besides mild depression, the CD group was characterized by higher anxiety scores $(7.93[6.59,9.26], P=0.002)$ (Additional file 1: Table S1) than the $\mathrm{CN}$ group. The CD group scored worse for quality of life as reflected by the St. George Questionnaire total score (ANCOVA, $P=0.011$; Fig. 1B) and the subscores Activity (ANCOVA, $P=0.021$ ), Impact (ANCOVA, $P=0.004$ ) and Symptoms (ANCOVA, $P=0.065$ ) subscores. Furthermore, the CD group was less physically active (ANCOVA, $P=0.031$; Fig. $1 C)$ and consumed more carbohydrates $(P=0.043$; Additional file 1: Table S1).

\section{Body composition and physical and cognitive function}

Body composition was not different between the CD and the $\mathrm{CN}$ groups as reflected by comparable values for lean mass, fat mass, and visceral adipose tissue (Additional file 1: Table S2). There was a trend for lower 6MWT (ANCOVA, $P=0.055$; Fig. 1D) in the CD group. Upper- and lower-limb muscle strength and endurance measurements and gait speed were not different (Additional file 1: Table S2). Although TMT and Stroop test scores were comparable between the CD and $\mathrm{CN}$ groups, the CD group was on average characterized by mild cognitive impairment as defined by Montreal
Cognitive Assessment (MoCA) scores $<26$ (Additional file 1: Table S2).

\section{Metabolic profiling Large neutral amino acid metabolism}

The sum plasma concentration of the large neutral amino acids (sumLNAAs) $(P=0.005)$ and branched chain amino acids (sumBCAAs) $(P=0.016)$ were reduced in the CD group (Fig. 2; Table 3). Specifically, tyrosine $(P=0.048)$, phenylalanine $(P=0.008)$, leucine $(P=0.031)$, and isoleucine $(P=0.003)$ were lower with a trending decrease in valine $(P=0.090)$. After correction for sumLNAA concentration, tyrosine (marker of dopamine synthesis) remained lower in $\mathrm{CD}(P=0.048)$, but tryptophan (marker of serotonin synthesis) was not different between the groups. Whole body production (WBP) of the individual LNAAs and the conversion of phenylalanine to tyrosine, reflecting postabsorptive net protein breakdown, were not different between the groups (Fig. 2). Clearance rates of phenylalanine (ANCOVA, $P=0.003$ ) and leucine (ANCOVA, $P=0.013$ ) were increased in the $C D$ group, with valine clearance tending to be lower (ANCOVA, $P=0.071$ ).

\section{Arginine and related amino acid metabolism}

Plasma concentrations (Fig. 3A; Table 4) or whole body production (Fig. 3B) of arginine, ornithine, and citrulline and conversion rates between arginine and citrulline (Fig. 3B) were not different between the $\mathrm{CN}$ and

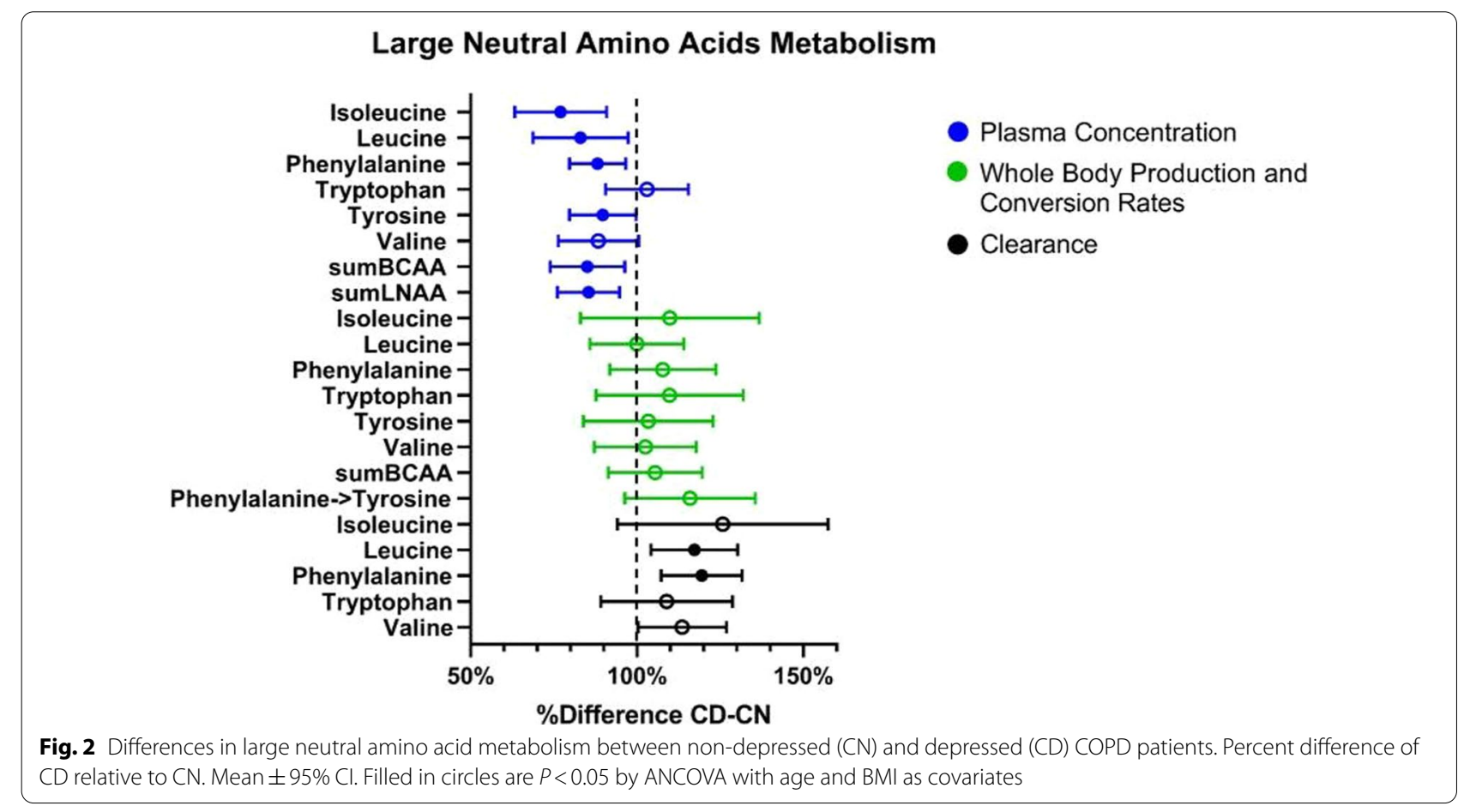


Table 3 Large neutral amino acid plasma concentrations, whole body production rates, and clearance rates in COPD non-depressed and COPD depressed

\begin{tabular}{|c|c|c|c|c|}
\hline & $\begin{array}{l}\text { COPD non-depressed (CN) } \\
(n=51)\end{array}$ & $\begin{array}{l}\text { COPD depressed (CD) } \\
(n=27)\end{array}$ & Estimated difference & $\begin{array}{l}\text { ANCOVA } \\
p \text { value }\end{array}$ \\
\hline \multicolumn{5}{|l|}{ Plasma concentrations $(\mu \mathrm{mol} / \mathrm{L})$} \\
\hline Tryptophan & $35.76[33.64,37.89]$ & $35.24[31.77,38.71]$ & $-0.26[-2.79,2.27]$ & 0.783 \\
\hline $\begin{array}{l}\text { Tryptophan corrected for large neutral } \\
\text { amino acids }\end{array}$ & & & $1.07[-3.39,5.53]$ & 0.656 \\
\hline Tyrosine & $54.23[50.65,57.80]$ & $47.11[43.14,51.08]$ & $-8.13[-13.63,-2.63]$ & 0.005 \\
\hline $\begin{array}{l}\text { Tyrosine corrected for large neutral } \\
\text { amino acids }\end{array}$ & & & $-5.58[-10.99,-0.17]$ & 0.048 \\
\hline Phenylalanine & $48.54[45.71,51.38]$ & $43.40[40.55,47.57]$ & $-5.75[-9.86,-1.64]$ & 0.008 \\
\hline Leucine & $110.50[98.87,122.10]$ & $95.95[79.09,106.70]$ & $-18.77[-34.54,-2.99]$ & 0.031 \\
\hline Isoleucine & $65.79[58.34,73.23]$ & $53.83[41.92,63.58]$ & $-15.11[-24.20,-6.02]$ & 0.003 \\
\hline Valine & $177.60[162.70,192.40]$ & $163.30[137.20,177.70]$ & $-20.67[-42.12,0.80]$ & 0.090 \\
\hline Sum branched chain amino acids & $332.40[306.40,358.40]$ & $294.70[243.10,327.90]$ & $-49.57[-86.83,-12.32]$ & 0.016 \\
\hline Sum large neutral amino acids & $435.20[406.50,463.90]$ & $385.20[322.20,430.30]$ & $-63.42[-104.03,-22.79]$ & 0.005 \\
\hline \multicolumn{5}{|l|}{ Whole body production rates $(\mu \mathrm{mol} / \mathrm{h})$} \\
\hline Phenylalanine & $3507.33[3250.40,3764.27]$ & $4022.20[3522.65,4521.75]$ & $271.60[-286.95,830.06]$ & 0.214 \\
\hline Tyrosine & $3188.99[2894.67,3483.31]$ & $3618.15[3059.27,4177.04]$ & $107.01[-514.88,728.98]$ & 0.581 \\
\hline Tryptophan & $1175.83[1026.55,1325.11]$ & $1326.93[1088.30,1565.57]$ & $114.50[-145.50,374.50]$ & 0.382 \\
\hline Isoleucine & $3673.94[3094.86,4253.01]$ & $3989.06[3155.51,4822.61]$ & $362.20[-623.90,1348.00]$ & 0.465 \\
\hline Valine & $11,119.21[9712.82,12,525.61]$ & $11,880.31[9962.54,11,602.38]$ & $276.61[-1423.95,1976.60]$ & 0.570 \\
\hline Leucine & $9782.64[8789.57,10,775.71]$ & $10,352.46[9102.55,12,188.00]$ & $-3.91[-1384.21,1376.47]$ & 0.811 \\
\hline $\begin{array}{l}\text { Phenylalanine to tyrosine (net protein } \\
\text { breakdown) }\end{array}$ & $216.80[179.40,235.00]$ & $267.50[200.50,287.20]$ & $34.51[-7.93,76.96]$ & 0.104 \\
\hline Branched chain amino acids & $24,783.00[21684.00,27,881.00]$ & $26,808.00[20235.00,31,134.00]$ & $1354.79[-2141.15,4851.15]$ & 0.315 \\
\hline \multicolumn{5}{|l|}{ Clearance rates $\left(\mathrm{L} \mathrm{h}^{-1}\right)$} \\
\hline Leucine & $1.98[1.79,2.18]$ & $2.24[1.78,2.64]$ & $0.34[0.08,0.60]$ & 0.013 \\
\hline Valine & $1.35[1.24,1.47]$ & $1.47[1.18,1.76]$ & $0.18[0.004,0.36]$ & 0.071 \\
\hline Isoleucine & $1.30[1.09,1.50]$ & $1.51[1.00,1.74]$ & $0.33[-0.08,0.74]$ & 0.133 \\
\hline Phenylalanine & $1.55[1.46,1.64]$ & $1.88[1.51,2.18]$ & $0.30[0.11,0.49]$ & 0.003 \\
\hline Tryptophan & $0.72[0.65,0.80]$ & $0.77[0.62,0.95]$ & $0.06[-0.08,0.21]$ & 0.371 \\
\hline
\end{tabular}

Values are mean [95\% Cl], except for when data was log-transformed for which geometric mean [95\% Cl] was used. LNAA: Large neutral amino acids. BCAA: Branched chain amino acids. WBP: Whole body production. Statistics are by ANCOVA with age and BMI as covariates, normal text is untransformed data and italicized is logtransformed data, bold is $P<0.05$

CD groups. While arginine clearance was not different between the groups (ANCOVA, $P=0.879$ ), citrulline clearance was increased (ANCOVA, $P=0.006$ ) and ornithine clearance tended to be increased (ANCOVA, $P=0.075)$ in the CD group (Fig. 3C).

\section{Remaining amino acid metabolism}

Comparable plasma concentrations, whole body production and clearance rates (Fig. 3A-C; Additional file 1: Table S3, Additional file 1: Table S4, Additional file 1: Table S5) were found for the remaining amino acids except for a lower plasma concentration of methionine (ANCOVA, $P=0.048$ ) (Fig. $3 \mathrm{~A}$ ) and increased production of histidine (ANCOVA, $P=0.044$ ) (Fig. 3B) in the CD group.
We also interrogated whether inclusion of antidepressant use, SSRI use, SNRI use, and anxiolytic use as covariates in our model would alter results and doing so did not alter our findings. In line with this, we found comparable significant findings when analyzing only subjects who used antidepressants in $\mathrm{CN}$ and $\mathrm{CD}$ groups (Additional file 1: Table S6, Additional file 1: Table S7, Additional file 1: Table S8, Additional file 1: Table S9, Additional file 1: Table S10), though sample sizes were smaller (CN $\mathrm{n}=23, \mathrm{CD} \mathrm{n}=15$ ).

\section{Discussion}

In this present study, we examined whether COPD patients with depressive symptoms were characterized by a specific clinical, functional and metabolic phenotype. 


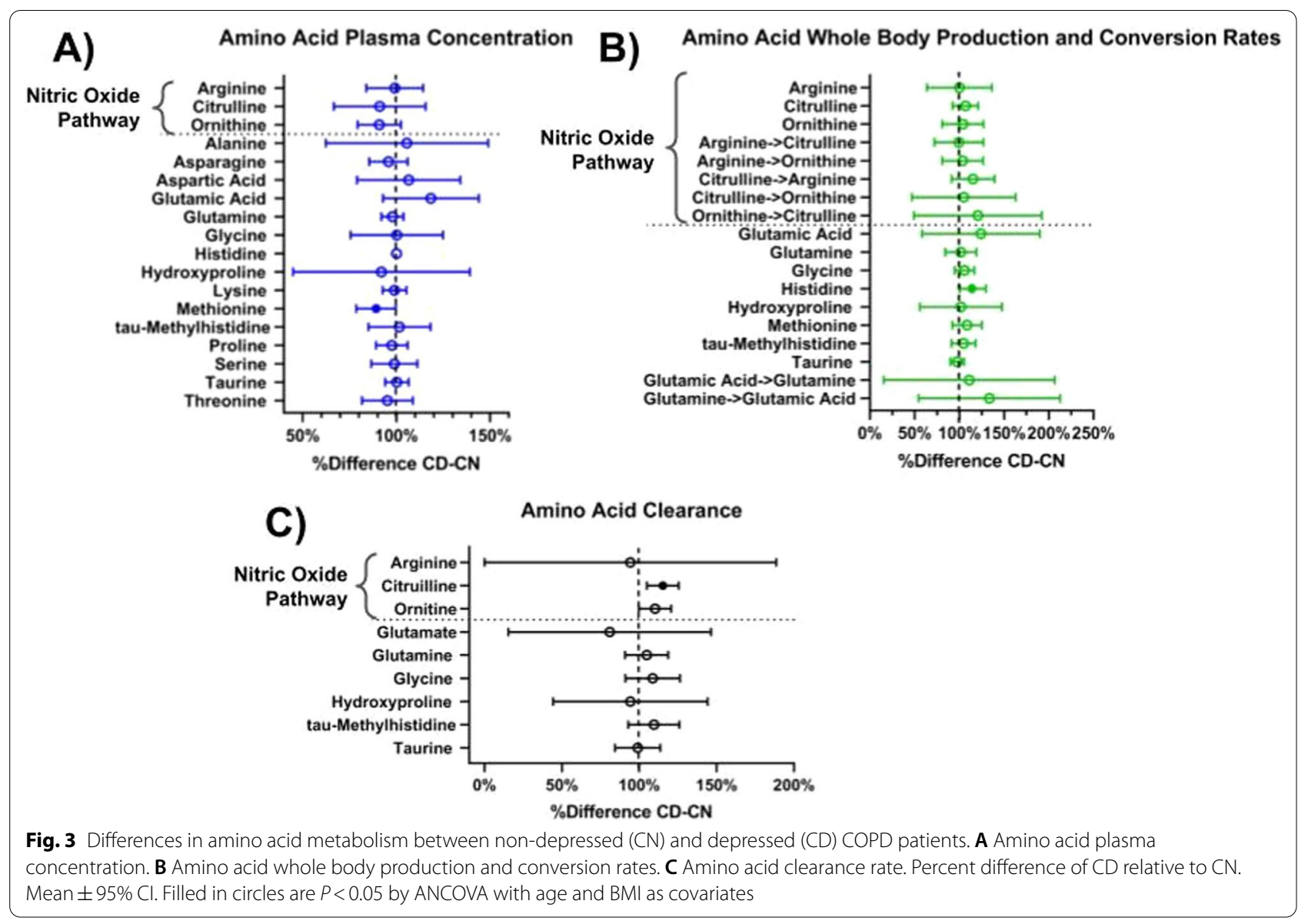

While there were no differences in lung function and disease history between the depressed (CD) and nondepressed $(\mathrm{CN})$ COPD groups, the impact of COPD on quality of life was higher in the CD group. Furthermore, the $C D$ patients were on average obese, and were characterized by shorter 6MWT distances, physical inactivity, and poor quality of life compared to the $\mathrm{CN}$ group. Metabolism of Large Neutral Amino Acids (LNAA) and particularly of the BCAA, was altered in the CD group.

For this study, 78 COPD outpatients were randomly recruited from the community. Prevalence of depression based on a depression score $\geq 8$ was $34.6 \%$ (27/78), which is in line with $33-57 \%$ of mild depression previously found (depression score: 8-11 or Geriatric Depression Scale score $\geq 11 / 30)[2-4,6]$. The depressed and non-depressed groups were of a similar age range (4676 years) and had comparable lung function characteristics, as previously observed [13-16, 18, 65]. Although elevated CRP levels are associated with depression [66], remarkably lower CRP values were found in the studied $\mathrm{CD}$ compared to $\mathrm{CN}$, though both groups had an elevated systemic inflammatory response (CRP levels $>3 \mathrm{mg} / \mathrm{L}$ ) [67]. Moreover, we observed no difference in the proportion of patients using antidepressants/anxiolytics between non-depressed COPD and those experiencing depression ( $48 \% \mathrm{CN}$ vs. $59 \% \mathrm{CD}$ ), suggesting there may be a subpopulation that either are non-adherent for medication use for reasons such as fear of sideeffects and stigma [68-70] or has treatment-resistant depression.

The present study examined whether disturbances in amino acid metabolism may play a role in the etiology of depression in COPD, as this information may aid in identifying specific nutritional targets of treatment. As multiple other factors may affect amino acid metabolism, we first examined whether our depressed subjects were characterized by certain daily functional, body composition, and lifestyle features.

\section{Physical muscle function, body composition, cognitive function, and quality of life}

We found a slight lower 6-min walk distance but not in muscle strength in the depressed COPD patients $[9,16$, $25,71,72]$, which might be explained by the lower daily physical activity level. In line, a 6-week exercise regimen previously found to lead to improved depressive 
Table 4 Arginine and related amino acids plasma concentrations, whole body production rates, and clearance rates in COPD nondepressed and COPD depressed

\begin{tabular}{|c|c|c|c|c|}
\hline & $\begin{array}{l}\text { COPD non-depressed }(\mathrm{CN}) \\
(\mathrm{n}=51)\end{array}$ & $\begin{array}{l}\text { COPD depressed (CD) } \\
(n=27)\end{array}$ & Estimated difference (t-test) & $\begin{array}{l}\text { ANCOVA } \\
p \text { value }\end{array}$ \\
\hline \multicolumn{5}{|l|}{ Plasma concentrations $(\mu \mathrm{mol} / \mathrm{L})$} \\
\hline Arginine & $69.46[62.83,76.10]$ & $68.22[54.30,75.72]$ & $-0.54[10.00,-11.08]$ & 0.943 \\
\hline Citrulline & $34.54[31.00,38.08]$ & $31.12[22.98,37.61]$ & $-3.07[-11.54,5.40]$ & 0.438 \\
\hline Ornithine & $55.70[51.75,59.66]$ & $51.89[44.19,63.77]$ & $-5.066[-11.49,1.35]$ & 0.140 \\
\hline \multicolumn{5}{|l|}{ Whole body production rates ( $\mu \mathrm{mol} / \mathrm{h})$} \\
\hline Arginine & $9405.40[7503.03,11,307.80]$ & $9394.86[8228.46,10,561.30]$ & $5.67[-3398.25,3409.58]$ & 0.855 \\
\hline Citrulline & $1028.99[950.60,1107.42]$ & $1124.34[989.04,1259.63]$ & $70.86[-76.83,218.60]$ & 0.334 \\
\hline Ornithine & $2031.62[1856.21,2207.03]$ & $2277.54[1954.20,2600.88]$ & $81.64[-386.24,549.71]$ & 0.544 \\
\hline $\begin{array}{l}\text { Citrulline to arginine (ARG de novo produc- } \\
\text { tion) }\end{array}$ & $1075.75[951.58,1199.93]$ & $1311.09[1072.80,1549.37]$ & $164.97[-93.01,422.81]$ & 0.224 \\
\hline Arginine to citrulline (NO production) & $389.80[154.50,625.20]$ & $372.80[82.24,247.60]$ & $-1.67[-108.32,105.00]$ & 0.974 \\
\hline Arginine to ornithine & $2258.60[1631.89,2885.32]$ & $2706.34[1709.68,3702.99]$ & $85.26[602.25,-431.73]$ & 0.819 \\
\hline Ornithine to citrulline & $116.50[97.74,135.20]$ & $145.00[118.10,187.70]$ & $24.12[-59.20,107.42]$ & 0.555 \\
\hline Citrulline to ornithine & $292.80[195.40,390.10]$ & $364.30[206.2,522.30]$ & $14.57[184.66,-155.53]$ & 0.902 \\
\hline \multicolumn{5}{|l|}{ Clearance rates $\left(\mathrm{L} \mathrm{h}^{-1}\right)$} \\
\hline Arginine & $3.00[2.51,3.49]$ & $2.843[2.52,3.34]$ & $-0.172[2.66,-3.00]$ & 0.879 \\
\hline Citrulline & $0.67[0.62,0.71]$ & $0.75[0.66,0.80]$ & $0.10[0.03,0.17]$ & 0.006 \\
\hline Ornithine & $0.79[0.73,0.84]$ & $0.86[0.71,1.00]$ & $0.08[-0.002,0.16]$ & 0.075 \\
\hline
\end{tabular}

Values are mean [95\% $\mathrm{Cl}]$, except for when data was log-transformed for which geometric mean [95\% Cl] was used. DLCO: diffusing capacity for carbon monoxide. WBP: Whole body production. Statistics are by ANCOVA with age and BMI as covariates, normal text is untransformed data and italicized is log-transformed data, bold is $P<0.05$

symptoms [13]. Depression in COPD was not associated with changes in BMI or body composition in line with previous studies $[9,16,18]$, though one study did identify higher levels of depression in underweight COPD patients [15] and others found an association with increased BMI [13, 14]. However, depression was associated with a reported lower quality of life and elevated CAT scores, consistent with previous studies regarding mildly depressed COPD patients [13, 15, 16, 18, 72]. Additionally, while $\mathrm{CD}$ on average had mild cognitive impairment (MoCA score of 24.9), there was no significant difference in cognitive function as assessed by STROOP and TMT tests between the CD and CN, consistent with one study showing only a trending association between cognitive impairment and depression [27] and another study finding only borderline significance for the copy drawing test, which assesses visuospatial and praxis skills [28]. This means if depression does impact cognitive function in COPD, it may be harder to discern due to the negative impact the presence of COPD already has on cognitive function.

\section{Large neutral amino acid metabolism}

In the present study, we examined plasma amino acid profile and whole-body production rates of amino acids known to play a role in mood (e.g. LNAA, BCAA, and arginine). We observed a decrease in all LNAA plasma concentrations except for tryptophan in the patients with depression. This decrease is due to increased clearance of some of the LNAAs (leucine, valine, phenylalanine) without a compensatory increase in their whole body productions. Normally, a reduced tryptophan:LNAA ratio is associated with depression [35, 73-75], the hypothesis being that this reduced ratio represents increased competition for the L-type amino acid carrier that LNAAs use to cross the blood-brain barrier, decreasing tryptophan availability for serotonin production [76]. However, decreased LNAA levels and comparable values were found for adjusted tryptophan plasma concentrations in our depressed COPD group. Elevated serotonin plasma levels were found in COPD patients and associated with worse symptoms and increased number of exacerbations $[77,78]$, with one study positing serotonin as a contributor in the pathogenesis of COPD [79]. Thus the decreased competition of Trp with other LNAAs and subsequent functional increase in availability may explain in part the decreased quality of life and worse disease severity reported in our study population. More research is needed to examine whether there is an insensitivity to serotonin signaling in the brains of COPD patients because despite the suggested elevated circulating serotonin there is still a higher rate of depression. 
Lower levels of BCAAs have previously been reported in individuals with COPD with low muscle mass [29, 80], however, fat-free mass of our studied CD group can be considered as normal. Reduced plasma BCAA concentrations have previously been proposed as a new biomarker for depression after identifying a negative correlation between BCAAs and depression scores [81]. Moreover, increased dietary intake of BCAAs were able to decrease the odds of depression in healthy adults [82], and depression scores improved after 4 months of leucine enriched nutritional supplementation in COPD [83].

One study revealed the underlying mechanism by which BCAAs impact mood by demonstrating that BCAAs supplementation promotes resilience in mice exposed to chronic defeat stress by increasing Brain Derived Neurotrophic Factor (BDNF)/TrkB (the receptor for BDNF) signaling in the hippocampus [84]. Exercise probably works via the same mechanism, promoting BDNF expression in the hippocampus [85], potentially revealing why a 6-week exercise regimen showed improved depressive symptoms [13]. Hallmarks of depression include decreased brain BDNF levels and TrkB signaling [86] as well as hippocampal degeneration [87]. Furthermore, decreased serum levels of irisin, a potent inducer of BDNF, is associated with increased mood disturbances in COPD [88] and hippocampal atrophy has been identified in COPD [89]. Increasing $\mathrm{BDNF} /$ TrkB signaling activates the mechanistic target of rapamycin complex 1 (mTORC1), which decreases depression in the brain [90]. Additionally, BCAAs, predominantly leucine, are capable of activating mTORC1 directly [91]. We hypothesize that mTORC1 activation in the hippocampus is taking a double hit due to lower BCAA levels identified in the CD group, indirectly by reduced stimulation of $\mathrm{BDNF} / \mathrm{TrkB}$ signaling and directly by reduced stimulation of mTORC1 itself, resulting in the observed depressive symptoms. The lower levels of BCAAs that individuals with COPD have independent of muscle function and body composition may therefore contribute to increased risk of developing depression.

Revealing mTORC1 as a potential mediator of depression in COPD also suggests considering use of alternative antidepressants as opposed to serotonin reuptake inhibitors (SSRIs), which are the current first line treatment for depression in COPD patients. Rapid acting antidepressants that promote mTORC1, such as low dose ketamine and scopolamine [92, 93], may be more effective and beneficial in the COPD population. Recently, the FDA has approved esketamine, the s-enantiomer of ketamine for treatment-resistant depression [94]. This new class of antidepressants that target mTORC1 may potentially prove more effective in depressed COPD patients while also minimizing side effects associated with SSRI use. Further research is needed in this area.

\section{Arginine and related amino acid metabolism}

We observed an increase in citrulline and ornithine clearance without other alterations in the arginine pathway in the CD group. Perturbations in the arginine pathway and metabolites have previously been associated with depression. Both human and animal studies have reported a link between dysregulation of plasma concentrations of arginine and related catabolic products and nitric oxide (NO) imbalance with pathophysiology of major depressive disorder (MDD) [38, 39, 95-98].

NO has been shown to modulate synthesis of monoamine neurotransmitters (norepinephrine, serotonin, dopamine) as well as influence the hypothalamus-pituitary-adrenal axis [99]. Our previous work comparing COPD patients to healthy controls found alterations in the arginine pathway $[31,33]$ and a higher NO production [31]. Our present data in CD only identified an increase in clearance of citrulline and ornithine, suggesting arginine metabolism and metabolites may not be underlying contributors to depression in COPD. Alternatively, our study predominantly recruited individuals with mild depression, experiencing depressive symptoms that may not reach the level of requirement for diagnosis of the previously studied MDD.

\section{Methionine metabolism}

We observed a decrease in the methionine plasma concentration, which is a key player in one-carbon metabolism, another pathway linked to depression. Methionine is converted by methionine adenosyltransferase to $S$-adenosyl-methionine (SAMe), which acts as a universal methyl donor for various important biological processes [100], including synthesis of monoamine neurotransmitters $[101,102]$. Moreover, the methionine cycle crucially interacts with the folate cycle, which is essential for the synthesis and regeneration of tetrahydrobiopterin [103], an important cofactor for enzymes that convert amino acids to monoamine neurotransmitters [104].

SAMe has been assessed in numerous trials over the years as a potential antidepressant [105], with some trials identifying SAMe as a potentially beneficial add-on in antidepressant therapy that enhances the effectiveness of the drug it is paired with [106]. If methionine levels are decreased in a particular patient population, it may create a predisposition for the development of depression. Our previous work has shown a decrease in methionine levels in COPD patients compared to healthy controls $[29,32]$, potentially explaining in part the increased risk of depression in this population. In the present study, decreased methionine concentration in the plasma with 
no compensatory elevation of methionine WBP was identified in depressed individuals with COPD. More studies are needed whether subsequent perturbations in one-carbon metabolism and neurotransmitter synthesis contribute to the depressive symptoms reported in these individuals.

\section{Limitations}

Although 78 COPD subjects were studied, the results might not be applicable to the general COPD population. Patients were those who voluntarily agreed to be part of the clinical trial and come in for questionnaires and testing, potentially excluding those suffering from moderate to severe depression, as is suggested by the average depression score in the $\mathrm{CD}$ group. This study is not powered for sex differences though some studies have shown association between female sex and depression in COPD populations $[9,14]$. Moreover, this study is not powered for age differences but we did initially see significantly lower age in the depressed group before controlling for age and BMI in order to complete the ANCOVA analysis. This initial finding is consistent with other studies $[9,65]$ and is a potential future direction as more are recruited for the clinical trial. Additionally, we attempted to answer the clinically important question of metabolomic differences underlying treatment-resistant depression in COPD by comparing antidepressant users of the $\mathrm{CN}$ and $\mathrm{CD}$ groups. While comparable findings were obtained, a larger sample size is still required to identify a distinguishing phenotype.

\section{Conclusion}

In conclusion, the present study revealed a set of metabolic changes in depressed COPD that include perturbation of large neutral amino acids and specifically BCAAs. Further research is warranted to determine if these disturbances are causative or consequences of depression in COPD. Though supplemental nutrition enriched in leucine has been shown to improve depressive symptoms during pulmonary rehabilitation, it remains to be shown that BCAA supplementation is beneficial for treating depression in COPD. Moreover, if BCAA imbalances and subsequent mTOR disturbances in the brain prove to be contributing factors to depression in COPD, newer antidepressants targeting mTOR may prove more effective in the COPD population. Ultimately, identification of an underlying metabolic phenotype in depressed COPD patients is critical to provide insight into potential nutritional and therapeutic treatments.

\section{Abbreviations}

BCAA: Branched chain amino acids; BDNF: Brain Derived Neurotrophic Factor; CAT: COPD assessment test; COPD: Chronic obstructive pulmonary disease;
CVD: Cardiovascular disease; FEV1: Forced expiratory volume in $1 \mathrm{~s}$; FFM: Fatfree mass; FFMI: Fat-free mass index; FM: Fat mass; FVC: Forced vital capacity; hs-CRP: High-sensitivity C-reactive protein; LNAA: Large neutral amino acids; MCl: Mild cognitive impairment; MDD: Major depressive disorder; MoCA: Montreal Cognitive Assessment; mTORC 1: Mechanistic target of rapamycin complex 1; NO: Nitric oxide; PASE: Physical Activity Scale for the Elderly Questionnaire; SAMe: S-Adenosyl-methionine; SCWTs: Stroop color-word tests; SGRQ: St. George Respiratory Questionnaire; TMT: Trail making test; QoL: Quality of life; WBP: Whole body production; 6MWT: 6-Min walk test.

\section{Supplementary Information}

The online version contains supplementary material available at https://doi. org/10.1186/s12890-021-01719-9.

Additional file 1: Supplementary Tables.

\section{Acknowledgements}

We sincerely thank all the subjects for their willingness to participate in this research study and all CTRAL personnel who have made this work possible.

\section{Authors' contributions}

MRP, NEPD, and MPKJE had full access to all of the data in the study and took responsibility for the integrity of the data and the accuracy of the data analysis. NEPD and MPKJE designed the research and were involved in recruitment of subjects, conduct of the study and sample analysis. RH and AJZ were involved in recruitment of subjects. MRP, NEPD, and MPKJE were involved in the data analysis, and writing of the manuscript. $\mathrm{RH}$ and AJZ reviewed and revised the manuscript. All authors read and approved the final manuscript.

\section{Funding}

This study was supported in part by National Heart, Lung, and Blood Institute of the National Institutes of Health, Grant Number R56HL141744. The content is solely the responsibility of the authors and does not necessarily represent the official views of the National Institutes of Health. The funding body played no role in the design of the study and collection, analysis, and interpretation of data and in writing the manuscript.

Availability of data and materials

The datasets generated and analyzed during the current study are available from the corresponding author on reasonable request.

\section{Declarations}

Ethics approval and consent to participate

All subjects were studied at the Clinical Research Unit of the Center for Translational Research in Aging and Longevity, housed at the Human Clinical Research Building, Texas A\&M University. Written informed consent was obtained from all subjects before any measurements were performed. The study was conducted in accordance with the Declaration of Helsinki, and the protocol was approved by the Institutional Review Board of Texas A\&M University and was registered on ClinicalTrials.gov (NCT01787682, NCT02770092, NCT02780219, NCT03796455).

\section{Consent for publication}

Not applicable.

\section{Competing interests}

The authors declare that they have no competing interests.

\section{Author details}

${ }^{1}$ Department of Health and Kinesiology, Center for Translational Research in Aging and Longevity, Texas A\&M University, College Station, TX, USA.

${ }^{2}$ Department of Neuroscience and Experimental Therapeutics, Texas A\&M University Health Science Center, Bryan, TX, USA. ${ }^{3}$ Pulmonary, Critical Care and Sleep Medicine, Scott and White Medical Center, College Station, TX, USA. 
Received: 28 July 2021 Accepted: 28 October 2021

Published online: 07 November 2021

\section{References}

1. Maurer J, Rebbapragada V, Borson S, Goldstein R, Kunik ME, Yohannes AM, et al. Anxiety and depression in COPD: current understanding, unanswered questions, and research needs. Chest. 2008;134(4 Suppl):43s-56s.

2. Lacasse Y, Rousseau L, Maltais F. Prevalence of depressive symptoms and depression in patients with severe oxygen-dependent chronic obstructive pulmonary disease. J Cardpulm Rehabil. 2001;21(2):80-6.

3. Lewis KE, Annandale JA, Sykes RN, Hurlin C, Owen C, Harrison NK. Prevalence of anxiety and depression in patients with severe COPD: similar high levels with and without LTOT. COPD. 2007;4(4):305-12.

4. Solano JP, Gomes B, Higginson IJ. A comparison of symptom prevalence in far advanced cancer, AIDS, heart disease, chronic obstructive pulmonary disease and renal disease. J Pain Symptom Manag. 2006;31(1):58-69.

5. Vanfleteren LEGW, Spruit MA, Groenen M, Gaffron S, van Empel VPM, Bruijnzeel PLB, et al. Clusters of comorbidities based on validated objective measurements and systemic inflammation in patients with chronic obstructive pulmonary disease. Am J Respir Crit Care Med. 2013;187(7):728-35.

6. Yohannes AM, Baldwin RC, Connolly MJ. Mood disorders in elderly patients with chronic obstructive pulmonary disease. Rev Clin Gerontol. 2000;10(2):193-202.

7. NIH. Major Depression 2019 [updated February 2019]. Available from https://www.nimh.nih.gov/health/statistics/major-depression.shtml.

8. Dalal AA, Shah M, Lunacsek O, Hanania NA. Clinical and economic burden of depression/anxiety in chronic obstructive pulmonary disease patients within a managed care population. COPD J Chronic Obstr Pulm Disease. 2011;8(4):293-9.

9. Hanania NA, Mullerova H, Locantore NW, Vestbo J, Watkins ML, Wouters EF, et al. Determinants of depression in the ECLIPSE chronic obstructive pulmonary disease cohort. Am J Respir Crit Care Med. 2011;183(5):604-11.

10. Ng T-P, Niti M, Tan W-C, Cao Z, Ong K-C, Eng P. Depressive symptoms and chronic obstructive pulmonary disease: effect on mortality, hospital readmission, symptom burden, functional status, and quality of life. Arch Intern Med. 2007;167(1):60-7.

11. Pooler A, Beech R. Examining the relationship between anxiety and depression and exacerbations of COPD which result in hospital admission: a systematic review. Int J Chronic Obstr Pulm Disease. 2014;9:315-30.

12. Dahlén I, Janson C. Anxiety and depression are related to the outcome of emergency treatment in patients with obstructive pulmonary disease. Chest. 2002;122(5):1633-7.

13. Catalfo G, Crea L, Lo Castro T, Magnano San Lio F, Minutolo G, Siscaro G, et al. Depression, body mass index, and chronic obstructive pulmonary disease - a holistic approach. Int J Chronic Obstr Pulm Disease. 2016;11:239-49.

14. Chavannes N, Huibers M, Schermer T, Hendriks A, van Weel C, Wouters $\mathrm{E}$, et al. Associations of depressive symptoms with gender, body mass index and dyspnea in primary care COPD patients. Fam Pract. 2005;22(6):604-7.

15. Janssen DJ, Spruit MA, Leue C, Gijsen C, Hameleers H, Schols JM, et al. Symptoms of anxiety and depression in COPD patients entering pulmonary rehabilitation. Chronic Respir Disease. 2010;7(3):147-57.

16. Al-shair K, Dockry R, Mallia-Milanes B, Kolsum U, Singh D, Vestbo J. Depression and its relationship with poor exercise capacity, BODE index and muscle wasting in COPD. Respir Med. 2009;103(10):1572-9.

17. Di Marco F, Verga M, Reggente M, Maria Casanova F, Santus P, Blasi F, et al. Anxiety and depression in COPD patients: the roles of gender and disease severity. Respir Med. 2006;100(10):1767-74.

18. Yohannes AM, Roomi J, Baldwin RC, Connolly MJ. Depression in elderly outpatients with disabling chronic obstructive pulmonary disease. Age Ageing. 1998;27(2):155-60.
19. Kim HFS, Kunik ME, Molinari VA, Hillman SL, Lalani S, Orengo CA, et al. Functional impairment in COPD patients: the impact of anxiety and depression. Psychosomatics. 2000;41(6):465-71.

20. Wall MP. Predictors of functional performance in community-dwelling people with COPD. J Nurs Scholarsh Off Publ Sigma Theta Tau Int Honor Soc Nurs. 2007;39(3):222-8.

21. Godoy RF, Teixeira PJ, Becker Junior B, Michelli M, Godoy DV. Long-term repercussions of a pulmonary rehabilitation program on the indices of anxiety, depression, quality of life and physical performance in patients with COPD. Jornal brasileiro de pneumologia: publicacao oficial da Sociedade Brasileira de Pneumologia e Tisilogia. 2009;35(2):129-36.

22. Trappenburg JC, Troosters T, Spruit MA, Vandebrouck N, Decramer M, Gosselink R. Psychosocial conditions do not affect short-term outcome of multidisciplinary rehabilitation in chronic obstructive pulmonary disease. Arch Phys Med Rehabil. 2005;86(9):1788-92.

23. Weaver TE, Richmond TS, Narsavage GL. An explanatory model of functional status in chronic obstructive pulmonary disease. Nurs Res. 1997:46(1):26-31.

24. Yeh ML, Chen HH, Liao YC, Liao WY. Testing the functional status model in patients with chronic obstructive pulmonary disease. J Adv Nurs. 2004:48(4):342-50.

25. Spruit MA, Watkins ML, Edwards LD, Vestbo J, Calverley PMA, Pinto-Plata $\checkmark$, et al. Determinants of poor 6-min walking distance in patients with COPD: the ECLIPSE cohort. Respir Med. 2010;104(6):849-57.

26. Jeong M, Kang HK, Song P, Park HK, Jung H, Lee S-S, et al. Hand grip strength in patients with chronic obstructive pulmonary disease. Int J Chronic Obstr Pulm Disease. 2017;12:2385-90.

27. Cleutjens FAHM, Spruit MA, Ponds RWHM, Vanfleteren LEGW, Franssen FME, Gijsen C, et al. Cognitive impairment and clinical characteristics in patients with chronic obstructive pulmonary disease. Chronic Respir Disease. 2018;15(2):91-102.

28. Pierobon A, Ranzini L, Torlaschi V, Sini Bottelli E, Giardini A, Bruschi C, et al. Screening for neuropsychological impairment in COPD patients undergoing rehabilitation. PLOS ONE. 2018;13(8):e0199736.

29. Engelen MP, Wouters EF, Deutz NE, Menheere PP, Schols AM. Factors contributing to alterations in skeletal muscle and plasma amino acid profiles in patients with chronic obstructive pulmonary disease. Am J Clin Nutr. 2000;72(6):1480-7.

30. Engelen MPKJ, Deutz NEP, Wouters EFM, Schols AMWJ. Enhanced levels of whole-body protein turnover in patients with chronic obstructive pulmonary disease. Am J Respir Crit Care Med. 2000;162(4):1488-92.

31. Engelen M, Jonker R, Thaden JJ, Ten Have GAM, Jeon MS, Dasarathy S, et al. Comprehensive metabolic flux analysis to explain skeletal muscle weakness in COPD. Clin Nutr. 2020;39(10):3056-65.

32. Engelen MPKJ, Wouters EFM, Deutz NEP, Does JD, Schols AMWJ. Effects of exercise on amino acid metabolism in patients with chronic obstructive pulmonary disease. Am J Respir Crit Care Med. 2001;163(4):859-64.

33. Jonker R, Deutz NE, Erbland ML, Anderson PJ, Engelen MP. Alterations in whole-body arginine metabolism in chronic obstructive pulmonary disease. Am J Clin Nutr. 2016;103(6):1458-64.

34. Pouw EM, Schols AMWJ, Deutz NEP, Wouters EFM. Plasma and muscle amino acid levels in relation to resting energy expenditure and inflammation in stable chronic obstructive pulmonary disease. Am J Respir Crit Care Med. 1998;158(3):797-801.

35. DeMyer MK, Shea PA, Hendrie HC, Yoshimura NN. Plasma tryptophan and five other amino acids in depressed and normal subjects. Arch Gen Psychiatry. 1981;38(6):642-6.

36. Fernstrom JD. Large neutral amino acids: dietary effects on brain neurochemistry and function. Amino Acids. 2013;45(3):419-30.

37. Jonker R, Engelen MPKJ, Deutz NEP. Role of specific dietary amino acids in clinical conditions. Br J Nutr. 2012;108(Suppl 2(02)):S139-48.

38. Ali-Sisto T, Tolmunen T, Viinamäki H, Mäntyselkä P, Valkonen-Korhonen $\mathrm{M}$, Koivumaa-Honkanen $\mathrm{H}$, et al. Global arginine bioavailability ratio is decreased in patients with major depressive disorder. J Affect Disord. 2018:229:145-51.

39. Hess S, Baker G, Gyenes G, Tsuyuki R, Newman S, Le Melledo J-M. Decreased serum $\mathrm{L}$-arginine and $\mathrm{L}$-citrulline levels in major depression. Psychopharmacology. 2017;234(21):3241-7.

40. Stern AF. The hospital anxiety and depression scale. Occup Med. 2014;64(5):393-4. 
41. Nguyen HQ, Fan VS, Herting J, Lee J, Fu M, Chen Z, et al. Patients with COPD with higher levels of anxiety are more physically active. Chest. 2013;144(1):145-51.

42. Xiao T, Qiu H, Chen Y, Zhou X, Wu K, Ruan X, et al. Prevalence of anxiety and depression symptoms and their associated factors in mild COPD patients from community settings, Shanghai, China: a cross-sectional study. BMC Psychiatry. 2018;18(1):89.

43. Löfberg E, Gutierrez A, Wernerman J, Anderstam B, Mitch WE, Price SR, et al. Effects of high doses of glucocorticoids on free amino acids, ribosomes and protein turnover in human muscle. Eur J Clin Investig. 2002;32(5):345-53.

44. Park JK, Deutz NEP, Cruthirds CL, Kirschner SK, Park H, Madigan ML, et al. Risk factors for postural and functional balance impairment in patients with chronic obstructive pulmonary disease. J Clin Med. 2020;9(2):609.

45. Washburn RA, Smith KW, Jette AM, Janney CA. The Physical Activity Scale for the Elderly (PASE): development and evaluation. J Clin Epidemiol. 1993;46(2):153-62

46. Jones PW, Harding G, Berry P, Wiklund I, Chen W-H, Kline LN. Development and first validation of the COPD assessment test. Eur Respir J. 2009;34(3):648-54.

47. Charlson M, Szatrowski TP, Peterson J, Gold J. Validation of a combined comorbidity index. J Clin Epidemiol. 1994;47(11):1245-51.

48. McNair DM, Lorr M, Droppleman LF. Revised manual for the profile of mood states. San Diego: Educational and Industrial Testing Services; 2003.

49. Jones PW, Quirk FH, Baveystock CM. The St. George's Respiratory Questionnaire. Respir Med. 1991;85:25-31.

50. Jones PW. St. George's Respiratory Questionnaire: MCID. COPD J Chronic Obstr Pulm Disease. 2005;2(1):75-9.

51. Vanltallie TB, Yang MU, Heymsfield SB, Funk RC, Boileau RA. Heightnormalized indices of the body's fat-free mass and fat mass: potentially useful indicators of nutritional status. Am J Clin Nutr. 1990;52(6):953-9.

52. Hankinson JL, Odencrantz JR, Fedan KB. Spirometric reference values from a sample of the general U.S. population. Am J Respir Crit Care Med. 1999;159(1):179-87.

53. Bohannon RW, Magasi SR, Bubela DJ, Wang Y-C, Gershon RC. Grip and knee extension muscle strength reflect a common construct among adults. Muscle Nerve. 2012;46(4):555-8

54. Saey D, Debigaré R, LeBlanc $P$, Mador MJ, Côté $C H$, Jobin J, et al. Contractile leg fatigue after cycle exercise. Am J Respir Crit Care Med. 2003;168(4):425-30.

55. ATS. ATS statement: guidelines for the 6-min walk test. Am J Respir Crit Care Med. 2002;166(1):111-7.

56. Sánchez-Cubillo I, Periáñez JA, Adrover-Roig D, Rodríguez-Sánchez JM, Ríos-Lago M, Tirapu J, et al. Construct validity of the trail making test: role of task-switching, working memory, inhibition/interference control, and visuomotor abilities. J Int Neuropsychol Soc JINS. 2009;15(3):438-50.

57. Lamers MJ, Roelofs A, Rabeling-Keus IM. Selective attention and response set in the Stroop task. Mem Cognit. 2010;38(7):893-904.

58. Stroop JR. Studies of interference in serial verbal reactions. J Exp Psychol. 1935;18(6):643-62.

59. Valentijn SAM, Van Boxtel MPJ, Van Hooren SAH, Bosma H, Beckers HJM Ponds RWHM, et al. Change in sensory functioning predicts change in cognitive functioning: results from a 6-year follow-up in the Maastricht Aging Study. J Am Geriatr Soc. 2005;53(3):374-80.

60. Deutz NEP, Thaden JJ, ten Have GAM, Walker DK, Engelen MPKJ. Metabolic phenotyping using kinetic measurements in young and older healthy adults. Metabolism. 2018;78:167-78.

61. Matthews DR, Hosker JP, Rudenski AS, Naylor BA, Treacher DF, Turner RC Homeostasis model assessment: insulin resistance and beta-cell function from fasting plasma glucose and insulin concentrations in man. Diabetologia. 1985;28(7):412-9.

62. Engelen MPKJ, Ten Have GAM, Thaden JJ, Deutz NEP. New advances in stable tracer methods to assess whole-body protein and amino acid metabolism. Curr Opin Clin Nutr Metab Care. 2019;22(5):337-46.

63. Mason A, Engelen M, Ivanov I, Toffolo GM, Deutz NEP. A four-compartment compartmental model to assess net whole body protein breakdown using a pulse of phenylalanine and tyrosine stable isotopes in humans. Am J Physiol Endocrinol Metab. 2017;313(1):E63-74.
64. Wolfe R, Chinkes D. Isotope tracers in metabolic research: principles and practice of kinetic analysis. New York: Wiley; 2005. p. 274.

65. Mi E, Mi E, Ewing G, Mahadeva R, Gardener AC, Holt Butcher H, et al. Associations between the psychological health of patients and carers in advanced COPD. Int J Chronic Obstr Pulm Disease. 2017;12:2813-21.

66. Osimo EF, Baxter LJ, Lewis G, Jones PB, Khandaker GM. Prevalence of low-grade inflammation in depression: a systematic review and metaanalysis of CRP levels. Psychol Med. 2019;49(12):1958-70.

67. Pearson TA, Mensah GA, Alexander RW, Anderson JL, Cannon RO, Criqui $M$, et al. Markers of inflammation and cardiovascular disease. Circulation. 2003;107(3):499-511.

68. Albrecht JS, Park Y, Hur P, Huang TY, Harris I, Netzer G, et al. Adherence to maintenance medications among older adults with chronic obstructive pulmonary disease: the role of depression. Ann Am Thorac Soc 2016;13(9):1497-504.

69. Sirey JA, Raue PJ, Alexopoulos GS. An intervention to improve depression care in older adults with COPD. Int J Geriatr Psychiatry. 2007;22(2):154-9.

70. Yohannes AM, Connolly MJ, Baldwin RC. A feasibility study of antidepressant drug therapy in depressed elderly patients with chronic obstructive pulmonary disease. Int J Geriatr Psychiatry. 2001;16(5):451-4.

71. Fan VS, Ramsey SD, Giardino ND, Make BJ, Emery CF, Diaz PT, et al. Sex, depression, and risk of hospitalization and mortality in chronic obstructive pulmonary disease. Arch Intern Med. 2007;167(21):2345-53.

72. von Leupoldt A, Taube K, Lehmann K, Fritzsche A, Magnussen H. The impact of anxiety and depression on outcomes of pulmonary rehabilitation in COPD. Eur Respir J. 2011;38(Suppl 55):p3638.

73. Lucca A, Lucini V, Catalano M, Alfano M, Smeraldi E. Plasma tryptophan to large neutral amino acids ratio and therapeutic response to a selective serotonin uptake inhibitor. Neuropsychobiology. 1994;29(3):108-11.

74. Møller SE, Bech P, Bjerrum H, Bøjholm S, Butler B, Folker H, et al. Plasma ratio tryptophan/neutral amino acids in relation to clinical response to paroxetine and clomipramine in patients with major depression. J Affect Disord. 1990;18(1):59-66.

75. Møller SE, de Beurs P, Timmerman L, Tan BK, Leijnse-Ybema HJ, Cohen Stuart $\mathrm{MH}$, et al. Plasma tryptophan and tyrosine ratios to competing amino acids in relation to antidepressant response to citalopram and maprotiline. Psychopharmacology. 1986;88(1):96-100.

76. Carlsson A, Lindqvist M. Dependence of 5-HT and catecholamine synthesis on concentrations of precursor amino-acids in rat brain. Naunyn Schmiedebergs Arch Pharmacol. 1978;303(2):157-64.

77. Pirina P, Zinellu E, Paliogiannis P, Fois AG, Marras V, Sotgia S, et al. Circulating serotonin levels in COPD patients: a pilot study. BMC Pulm Med. 2018;18(1):167

78. Meier MA, Ottiger M, Vögeli A, Steuer C, Bernasconi L, Thomann R, et al. Activation of the serotonin pathway is associated with poor outcome in COPD exacerbation: results of a long-term cohort study. Lung. 2017;195(3):303-11.

79. Lau WKW, Chan-Yeung MMW, Yip BHK, Cheung AHK, Ip MSM, Mak JCW, et al. The role of circulating serotonin in the development of chronic obstructive pulmonary disease. PLoS ONE. 2012;7(2):e31617.

80. Yoneda T, Yoshikawa M, Fu A, Tsukaguchi K, Okamoto Y, Takenaka H. Plasma levels of amino acids and hypermetabolism in patients with chronic obstructive pulmonary disease. Nutrition. 2001;17(2):95-9.

81. Baranyi A, Amouzadeh-Ghadikolai $O$, von Lewinski D, Rothenhäusler $\mathrm{H}-\mathrm{B}$, Theokas $\mathrm{S}$, Robier $\mathrm{C}$, et al. Branched-chain amino acids as new biomarkers of major depression-a novel neurobiology of mood disorder. PLOS ONE. 2016;11(8):e0160542-e.

82. Koochakpoor G, Salari-Moghaddam A, Keshteli AH, Afshar H, Esmaillzadeh A, Adibi P. Dietary intake of branched-chain amino acids in relation to depression, anxiety and psychological distress. Nutr J. 2021;20(1):11.

83. van de Bool C, Rutten EPA, van Helvoort A, Franssen FME, Wouters EFM, Schols AMWJ. A randomized clinical trial investigating the efficacy of targeted nutrition as adjunct to exercise training in COPD. J Cachexia Sarcopenia Muscle. 2017;8(5):748-58.

84. Nasrallah P, Haidar EA, Stephan JS, El Hayek L, Karnib N, Khalifeh M, et al. Branched-chain amino acids mediate resilience to chronic social defeat stress by activating BDNF/TRKB signaling. Neurobiol Stress. 2019;11:100170. 
85. Wrann Christiane D, White James P, Salogiannnis J, Laznik-Bogoslavski D, Wu J, Ma D, et al. Exercise induces hippocampal BDNF through a PGC-1a/FNDC5 Pathway. Cell Metab. 2013;18(5):649-59.

86. Lee B-H, Kim Y-K. The roles of BDNF in the pathophysiology of major depression and in antidepressant treatment. Psychiatry Investig. 2010;7(4):231-5

87. Gradin VB, Pomi A. The role of hippocampal atrophy in depression: a neurocomputational approach. J Biol Phys. 2008;34(1-2):107-20.

88. Papp C, Pak K, Erdei T, Juhasz B, Seres I, Szentpéteri A, et al. Alteration of the irisin-brain-derived neurotrophic factor axis contributes to disturbance of mood in COPD patients. Int J Chronic Obstr Pulm Disease. 2017;12:2023-33.

89. Li J, Fei $\mathrm{G}-\mathrm{H}$. The unique alterations of hippocampus and cognitive impairment in chronic obstructive pulmonary disease. Respir Res. 2013;14(1):140.

90. Wohleb ES, Gerhard D, Thomas A, Duman RS. Molecular and cellular mechanisms of rapid-acting antidepressants ketamine and scopolamine. Curr Neuropharmacol. 2017:15(1):11-20.

91. Manifava M, Smith M, Rotondo S, Walker S, Niewczas I, Zoncu R, et al. Dynamics of mTORC1 activation in response to amino acids. eLife. 2016;5:e19960.

92. Furey ML, Drevets WC. Antidepressant efficacy of the antimuscarinic drug scopolamine: a randomized, placebo-controlled clinical trial. Arch Gen Psychiatry. 2006;63(10):1121-9.

93. Zarate CA Jr, Singh JB, Carlson PJ, Brutsche NE, Ameli R, Luckenbaugh DA, et al. A randomized trial of an N-methyl-D-aspartate antagonist in treatment-resistant major depression. Arch Gen Psychiatry. 2006;63(8):856-64.

94. Kim J, Farchione T, Potter A, Chen Q, Temple R. Esketamine for treatment-resistant depression - first FDA-approved antidepressant in a new class. N Engl J Med. 2019;381(1):1-4.

95. Baranyi A, Amouzadeh-Ghadikolai O, Rothenhäusler H-B, Theokas S, Robier C, Baranyi M, et al. Nitric oxide-related biological pathways in patients with major depression. PLoS ONE. 2015;10(11):e0143397.

96. Jesse CR, Bortolatto CF, Savegnago L, Rocha JBT, Nogueira CW. Involvement of L-arginine-nitric oxide-cyclic guanosine monophosphate pathway in the antidepressant-like effect of tramadol in the rat forced swimming test. Prog Neuropsychopharmacol Biol Psychiatry. 2008;32(8):1838-43.

97. Lu Y-R, Zhang Y, Rao Y-B, Chen X, Lou H-F, Zhang Y, et al. The changes in, and relationship between, plasma nitric oxide and corticotropinreleasing hormone in patients with major depressive disorder. Clin Exp Pharmacol Physiol. 2018;45(1):10-5.

98. Ozden A, Angelos H, Feyza A, Elizabeth W, John P. Altered plasma levels of arginine metabolites in depression. J Psychiatr Res. 2020;120:21-8.

99. Dhir A, Kulkarni SK. Nitric oxide and major depression. Nitric Oxide. 2011;24(3):125-31.

100. Lu SC. S-Adenosylmethionine. Int J Biochem Cell Biol. 2000;32(4):391-5.

101. Otero Losada ME, Rubio MC. Acute effects of S-adenosyl-L-methionine on catecholaminergic central function. Eur J Pharmacol. 1989;163(2):353-6.

102. Otero-Losada ME, Rubio MC. Acute changes in 5-HT metabolism after S-adenosyl-L-methionine administration. Gen Pharmacol Vasc Syst. 1989;20(4):403-6.

103. Miller AL. The methylation, neurotransmitter, and antioxidant connections between folate and depression. Altern Med Rev J Clin Ther. 2008:13(3):216-26.

104. Sumi-Ichinose C, Urano F, Kuroda R, Ohye T, Kojima M, Tazawa M, et al. Catecholamines and serotonin are differently regulated by tetrahydrobiopterin: a study from 6-pyruvoyltetrahydropterin synthase knockout mice*. J Biol Chem. 2001;276(44):41150-60.

105. Cuomo A, Beccarini Crescenzi B, Bolognesi S, Goracci A, Koukouna D, Rossi R, et al. S-Adenosylmethionine (SAMe) in major depressive disorder (MDD): a clinician-oriented systematic review. Ann Gen Psychiatry. 2020;19(1):50

106. Turner $\mathrm{P}$, Kantaria $\mathrm{R}$, Young $\mathrm{AH}$. A systematic review and meta-analysis of the evidence base for add-on treatment for patients with major depressive disorder who have not responded to antidepressant treatment: a European perspective. J Psychopharmacol. 2014;28(2):85-98.

\section{Publisher's Note}

Springer Nature remains neutral with regard to jurisdictional claims in published maps and institutional affiliations.
Ready to submit your research? Choose BMC and benefit from:

- fast, convenient online submission

- thorough peer review by experienced researchers in your field

- rapid publication on acceptance

- support for research data, including large and complex data types

- gold Open Access which fosters wider collaboration and increased citations

- maximum visibility for your research: over $100 \mathrm{M}$ website views per year

At $\mathrm{BMC}$, research is always in progress.

Learn more biomedcentral.com/submissions 